\title{
Reply to: Challenging the paradigm
}

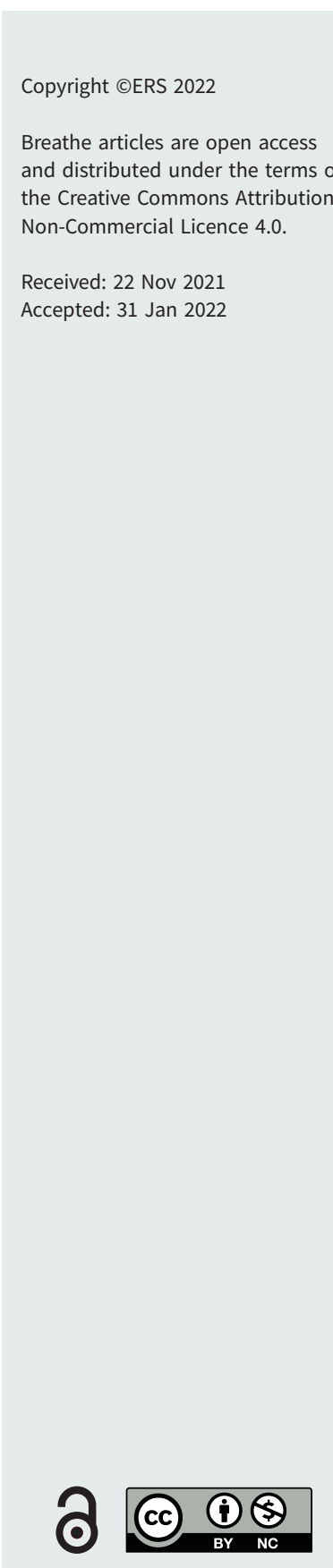

Copyright @ERS 2022

Breathe articles are open access and distributed under the terms of the Creative Commons Attribution Received: 22 Nov 2021 Accepted: 31 Jan 2022

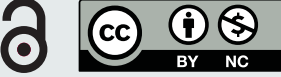

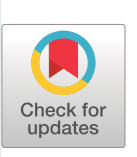

\section{Reply to M.L. Everard:}

We thank M.L. Everard for his interest in our article [1] and thank the Editors for giving us the opportunity to respond. Space constraints precluded us describing the detailed management of extrapulmonary treatable traits, hence the educational aim was to begin to appreciate, but we are happy to refer interested readers to other review articles on the subject [2-4].

M.L. Everard appears to confuse the terms asthma and airway eosinophilia and their relationship to inhaled steroid treatment (ICS). The clinical definition of asthma (wheeze, chest tightness, dyspnoea and sometimes increased cough, advocated by the Lancet commission [5]) has many underlying phenotypes and endotypes, of which eosinophilic inflammation is but one; we are not quite sure what M.L. Everard means by describing asthma as a "discrete" condition. Of course, there are many actions of ICS [6], but these are highly unlikely to be of clinical relevance to non-eosinophilic asthma. In one study, asthmatic patients who were not eosinophilic were equally likely to respond to placebo or ICS and more likely to respond to tiotropium [7]. In our view, this study allays concerns about not using ICS in non-eosinophilic asthmas, although it could also be argued that better biomarkers for steroid responsiveness are needed. We accept that this study is short-term, and longer term data should be acquired. If ICS are given to all preschool wheezers there is no benefit [8]. However, the INFANT study [9] clearly showed that targeting ICS only to those preschool wheezers with (indirect) evidence of airway eosinophilia was safe and effective, emphasising the importance of targeting ICS to eosinophilic airway disease, and the futility of using them in non-eosinophilic disease. Also, we have shown good agreement between peripheral blood and bronchoalveolar lavage eosinophilia in preschool children [10]. There needs to be a bigger trial of eosinophil-guided therapy in children; a post-hoc and therefore hypothesis generating analysis of this approach did indeed show a reduction in asthma attacks, but only in the 4 weeks after measuring eosinophils in sputum and using them to guide results [11]. Of course the measurement of sputum eosinophils is variable [12], as is so much of what we grapple with in respiratory medicine, but this does not mean we should wring our hands and walk away. Our "obsession" with the eosinophil is not unconnected with the huge success of biologicals targeting Type 2 inflammation when it is present, and irrespective of whether the label "asthma” or "chronic obstructive pulmonary disease (COPD)" is applied [13]; presumably no-one would advocate giving these to non-eosinophilic patients? Of course it is important that those with a steroid responsive condition are treated with ICS, and nowhere are we advocating against this; but just because guidelines, often based on the flimsiest evidence which is all that is available, make recommendations does not mean they should be uncritically followed.

Another issue raised by M.L. Everard is the use of long- (LABA) and short-acting $\beta_{2}$-agonists (SABA) with and without concomitant ICS therapy. There is no doubt that SABA over-use and ICS under-use is dangerous in school-age and adult eosinophilic asthma [14], and that LABA should never be prescribed without ICS in this context. However, those COPD patients who are not eosinophilic are legitimately prescribed LABA without ICS, and non-eosinophilic preschool wheezers can legitimately be prescribed SABA without ICS. As emphasised by the Lancet commission [5], the best approach is to understand what is going on in the airway, rather than hide under umbrella terms like "asthma” and "COPD”. If in so doing episodic eosinophilic airway inflammation is thought to be a possibility, then as needed ICS/rapid-onset $\beta$-agonist may be a perfectly reasonable approach.

In terms of the management of acute attacks with oral corticosteroids, again these are clearly lifesaving in school-age children and adults, but useless in preschool children, this last highlighting that acute wheeze

Shareable abstract (@ERSpublications)

Inhaled corticosteroids should be targeted to those with documented airway eosinophilia, not prescribed indiscriminately to all who wheeze. Blind steroid treatment without regard to underlying pathophysiology is not 21st century standard of care. https://bit.ly/34lyaJG

Cite this article as: Bush A, Pavord ID. Reply to: Challenging the paradigm. Breathe 2022; 18: 210174 [DOI: 10.1183/20734735.0174-2021]. 
does not always need this treatment [15]. Intriguingly, whereas some adult asthma attacks are undoubtedly eosinophilic, others are infective and non-eosinophilic [16], and yet we treat them the same way, which does not seem logical. Instead of uncritically reading guidelines, critical thought about the nature of the underlying disease is in order. This is especially needful if we propose to use a Type 2 monoclonal antibody as part of the acute treatment of asthma [17, 18], to try to reduce the danger of death in the crucial 4-week window after admission to hospital [14].

We agree that the airway microbiome is a topic of immense importance, albeit it was outside the remit of our article. It should be remembered that ICS have effects on the microbiome [19], and we little understand the consequences of this. This again underscores the need to use these powerful medications in a responsible and targeted fashion.

Finally, we agree with M.L. Everard's comments on the Finnish Asthma programme, and the need to get the basics right, which was not central to our commissioning brief, but obviously important [2-4]. Indeed, we have ourselves highlighted that children are being let down [20], and that we need not more guidelines but actually to implement what we already have [21]. This will not be achieved by giving ICS indiscriminately, or by thinking that an umbrella term is a "discrete condition" or even a diagnosis (any more than is "anaemia" a diagnosis!), but by measuring what we are trying to treat and the response to treatment using a personalised approach. Prescribe ICS for ICS-responsive disease, and ensure they are used effectively, because this saves lives; but do not give a good treatment a bad name by inappropriate use. The end game, of course, is to tease out specific endotypes in what is very far from being a "discrete" condition, and target them on an individual basis, as has been achieved so brilliantly in the field of cystic fibrosis. But in the meantime, just as medicines which lower blood pressure are reserved for those with hypertension, do not treat people with medications targeting a condition they do not have.

\section{Andrew Bush ${ }^{1,2}$ and Ian D. Pavord ${ }^{3}$}

${ }^{1}$ Paediatrics and Paediatric Respirology, Imperial Centre for Paediatrics and Child Health, Imperial College London, London, UK. ${ }^{2}$ Royal Brompton and Harefield NHS Foundation Trust, London, UK. ${ }^{3}$ Respiratory Medicine, Respiratory Medicine Unit and Oxford Respiratory NIHR BRC, Nuffield Department of Medicine, University of Oxford, Oxford, UK.

Corresponding author: Andrew Bush (A.Bush@rbht.nhs.uk)

Conflict of interest: A. Bush has nothing to disclose. I.D. Pavord reports speaker fees from Aerocrine AB; speaker fees and consultant fees from Almirall and Novartis; speaker fees, payments for organisation of educational events, consultant fees and international scientific meeting sponsorship from AstraZeneca, GSK, Regeneron Pharmaceuticals, Inc, Sanofi, Teva; speaker fees, consultant fees and international scientific meeting sponsorship from Boehringer Ingelheim; grants, speaker fees, consultant fees and international scientific meeting sponsorship from Chiesi; consultant fees from Circassia, Dey Pharma, Genentech, Knopp Biosciences, Merck, MSD, RespiVert, Schering-Plough; and consultant fees and international scientific meeting sponsorship from Napp Pharmaceuticals, outside the submitted work.

\section{References}

1 Bush A, Pavord ID. Challenging the paradigm: moving from umbrella labels to treatable traits in airway disease. Breathe 2021; 17: 210053.

2 Bush A, Fleming L, Saglani S. Severe asthma in children. Respirology 2017; 22: 886-897.

3 Cook J, Beresford F, Fainardi V, et al. Managing the paediatric patient with refractory asthma: a multidisciplinary approach. J Asthma Allergy 2017; 10: 123-130.

4 Saglani S, Fleming L, Sonnappa S, et al. Advances in the aetiology, management, and prevention of acute asthma attacks in children. Lancet Child Adolesc Health 2019; 3: 354-364.

5 Pavord ID, Beasley R, Agusti A, et al. After asthma: redefining airways diseases. Lancet 2018; 391: 350-400.

6 de Benedictis FM, Bush A. Corticosteroids in respiratory diseases in children. Am J Respir Crit Care Med 2012; 185: $12-23$.

7 Lazarus SC, Krishnan JA, King TS, et al. Mometasone or tiotropium in mild asthma with a low sputum eosinophil level. N Engl J Med 2019; 380: 2009-2019.

8 Grigg J, Nibber A, Paton JY, et al. Matched cohort study of therapeutic strategies to prevent preschool wheezing/asthma attacks. J Asthma Allergy 2018; 11: 309-321. 
$9 \quad$ Fitzpatrick AM, Jackson DJ, Mauger DT, et al. Individualized therapy for persistent asthma in young children. J Allergy Clin Immunol 2016; 138: 1608-1618.e12.

10 Jochmann A, Artusio L, Robson K, et al. Infection and inflammation in induced sputum from preschool children with chronic airways diseases. Pediatr Pulmonol 2016; 51: 778-786.

11 Fleming L, Wilson N, Regamey N, et al. Use of sputum eosinophil counts to guide management in children with severe asthma. Thorax 2012; 67: 193-198.

12 Fleming L, Tsartsali L, Wilson N, et al. Sputum inflammatory phenotypes are not stable in children with asthma. Thorax 2012; 67: 675-681.

13 Holguin F, Cardet JC, Chung KF, et al. Management of severe asthma: a European Respiratory Society/ American Thoracic Society guideline. Eur Respir J 2020; 55: 1900588.

14 Royal College of Physicians. Why asthma still kills: the National Review of Asthma Deaths (NRAD) Confidential Enquiry report. London, RCP, 2014. www.asthma.org.uk/globalassets/campaigns/nrad-full-report.pdf

15 Castro-Rodriguez JA, Beckhaus AA, Forno E. Efficacy of oral corticosteroids in the treatment of acute wheezing episodes in asthmatic preschoolers: Systematic review with meta-analysis. Pediatr Pulmonol 2016; 51: 868-876.

16 Poznanski SM, Mukherjee M, Zhao N, et al. Asthma exacerbations on benralizumab are largely non-eosinophilic. Allergy 2021; 76: 375-379.

17 Nowak RM, Parker JM, Silverman RA, et al. A randomized trial of benralizumab, an antiinterleukin 5 receptor alpha monoclonal antibody, after acute asthma. Am J Emerg Med 2015; 33: 14-20.

18 Ramakrishnan S, Camp JR, Vijayakumar B, et al. The use of benralizumab in the treatment of near-fatal asthma: a new approach. Am J Respir Crit Care Med 2020; 201: 1441-1443.

19 Leitao Filho FS, Takiguchi H, Akata K, et al. Effects of inhaled corticosteroid/long-acting $\beta_{2}$-agonist combination on the airway microbiome of patients with chronic obstructive pulmonary disease: a randomized controlled clinical trial (DISARM). Am J Respir Crit Care Med 2021; 204: 1143-1152.

20 Levy ML, Fleming L, Warner JO, et al. Paediatric asthma care in the UK: fragmented and fatally fallible. Br J Gen Pract 2019: 69: 405-406.

21 Bush A, Pavord ID. Forthcoming UK asthma guidelines: an opportunity to improve asthma outcomes. Lancet 2021; 398: 1856-1858. 